\title{
Environmental Sustainability through Green Business Process Management
}

\author{
Shahrzad Roohy Gohar \\ UQ Business School \\ University of Queensland \\ sh.roohygohar@business.uq.edu.au
}

\author{
Marta Indulska \\ UQ Business School \\ University of Queensland
}

\section{Abstract}

The climate change phenomenon, directly or indirectly, affects industries and nations. Governments and organizations have been challenged to identify their environmental impacts to address environmental sustainability issues. A promising, yet under-studied in this context, theme of information systems (IS) literature that has the potential to help with identifying, quantifying and managing environmental impacts is business process management (BPM). With its focus on continual process performance improvement, the capacity of BPM to contribute to Environmental Sustainability (ES) needs to be further explored. Yet, contributions from the BPM research community and the impact of these contributions appear to be fragmented. In this paper, we present a systematic literature review to explore BPM contributions to ES, with a focus on environmental performance indicators (EPIs) as well as relevant organizational factors related to ES and BPM. In doing so, we identify and explore 'Green BPM' contributions and suggest ways to advance BPM research in the context of ES.

Keywords: Environmental sustainability, Green BPM, Environmental performance indicators (EPIs)

\section{Introduction}

Sustainability has, at its core, the principle of continual and mindful growth, supporting societies, and maintaining economic performance without compromising the natural environment (Brown et al., 1987; WCED, 1987). Environmental sustainability (ES) in particular, with its focus on sustaining the living (Goodland, 1995), has become of increasing concern due to mankind's exploitation of natural resources. Recently, the United Nation's sustainable development goals (United Nations, 2016) came into force with 175 world leaders agreeing to increase their efforts through research and practice to tackle climate change. As part of this initiative, organizations are required to proactively manage the use of their natural resources and continuously improve their environmental performance.

Such continual improvement of environmental performance is achievable through the identification and measurement of environmental performance indicators (EPIs). EPIs are metrics that organizations use to measure environmental performance and to calculate their impact on the environment (Epstein \& Roy, 2001; IPCC, 2014; Jamous \& Müller, 2013; Jasch, 2000; Young \& Rikhardsson, 1996). Core EPIs include measures of water consumption, energy consumption, waste management, recycling, and $\mathrm{CO}_{2}$ and GHG emissions, and are commonly used by a wide range of industry sectors (Epstein \& Roy, 2001; IPCC, 2014; Jamous \& Müller, 2013; Jasch, 2000; Young \& Rikhardsson, 1996). It is thus important to consider how these EPIs 
can be managed and continually improved as organisations carry out their operations. In this context, we consider the field of Business Process Management (BPM), which has at its core the continuous improvement of processes and their key performance indicators (KPIs), and explore its contributions to ES with a specific lens on EPIs.

We refer to BPM research concerning ES as 'Green BPM'. The term is used by Seidel et al. (2012) to include understanding, documenting, executing and continually improving processes by focusing on their environmental impacts. Broadly, Green BPM supports the design and implementation of environmentally sustainable processes. In the context of IS, Opitz et al. (2014b) defined Green BPM as all IS-supported management activities that reduce the environmental impact of business processes, including design, improvement, process lifecycle and operational steps. The outlook of Green BPM is promising, yet the body of research focusing on ES remains lean (Maciel, 2017). Indeed, there is "a significant gap" between global calls to resolve climate change issues and what IS discipline research offers (Gholami et al., 2016), based on the number of IS research studies in the last decade that focus on sustainability (Chen et al., 2011; Gholami et al., 2016). The same trend is observed in BPM academic literature addressing sustainability (Hernández González et al., 2019). It is also unclear to what extent Green BPM has been studied and how it has contributed to the ES body of knowledge. To explore this notion, we conduct a systematic literature review (SLR) (Kitchenham et al., 2009) of Green BPM literature.

Our review aims to identify relevant contributions of BPM to EPIs and organizational factors relating to ES (Brooks et al., 2012) and to understand the extent of BPM research contribution to ES. Thus, our study explores how EPI and ES concepts have been addressed in BPM literature and suggests further research opportunities. Our study also explores the extent of alignment of these contributions with the focus of industry on various EPIs. Understanding this alignment is particularly important as it is an indicator of the relevance of Green BPM research to the needs of industry (Applegate \& King, 1999; Rosemann \& Vessey, 2008).

The structure of the paper is as follows. Section 2 provides a background to ES and BPM. Related studies that identify BPM contributions to ES are summarized in Section 3. Our methodology is presented in Section 4. Section 5 discusses the results of our systematic literature review and contrasts these with an industry focus. Finally, Sections 6 and 7 propose next steps and offer final remarks.

\section{Background}

The calls to focus on the environment and to change industrial practices began with the Brundtland Report published by the World Commission for Environment and Development (1987). Since then, sustainability-related studies have accelerated in various research disciplines (Dehghanian \& Mansour, 2009). While some researchers consider ecological concerns or social responsibility as sustainability (Linnenluecke \& Griffiths, 2010), current research looks more to the relationship between the three pillars of corporate sustainability (Elkington, 1998; Epstein \& Roy, 2001; Savitz, 2012). Namely: (1) economic, referring to economic capital; (2) social, referring to the equitable redistribution of resources; and (3) environmental, referring to natural capital (Goodland, 1995). These pillars of corporate sustainability are referred as the "triple bottom line" (Elkington, 1998; Savitz, 2012). Since the late 1990s, sustainability studies have focused on these pillars and applied them to advancing technologies and growing consumer demand. Our focus in this study is on the environmental 
pillar and in the context of Information Systems research, specifically Business Process Management.

\subsection{Environmental Sustainability and Information Systems}

While information technology (IT) is responsible for producing a large volume of air and water-polluting waste in its manufacture, operations and disposal, it also allows resource use to be captured, monitored and controlled in all areas of business and industry. Indeed, utilizing IT and IS for this purpose is expected to reduce carbon emissions in businesses by up to 15 percent by 2020 (Lacy et al., 2010), thus contributing positively to ES.

Increasing pressure from environmental legislation, and from consumers, motivates organizations to reduce the environmental impact of their practices (Bansal \& Roth, 2000; Lintukangas et al., 2016; Rajeev et al., 2017), motivating businesses to further invest in IS solutions (Lane et al., 2011) and implement environmental management systems (EMS) (Tinsley \& Pillai, 2006; Whitelaw, 2004). An EMS encompasses the organizational structure, technological resources, practices, processes and information resources for determining and implementing environmental policies (British Standards Institution, 1994). Many organizations have implemented an EMS to improve their compliance with environmental regulations and to reduce their environmental impact and improve their reputation (Sullivan \& Wyndham, 2001; Tinsley \& Pillai, 2006). Indeed by 2013, businesses compliant with the ISO14001 standard were spread across 170 countries (International Organisation for Standardization, 2013). ISO14001 provides organizations with a framework to develop their environmental objectives, measure the environmental impact of their operations, and monitor improvement and compliance with environmental regulations (Melnyk et al., 2003; Phan \& Baird, 2015; Wathern, 2013; Whitelaw, 2004). It is not the only example of a standard that provides IS solutions, integrating ES into all aspects of business.

Numerous IS-aided solutions and approaches exist to assist estimating the environmental impact of products, services and operations, such as lifecycle assessment (LCA) (Guinée, 2001) and environmental input-output analysis (EIO). LCA, which is also part of ISO14000, provides a method to assess the impact of materials from their initial use to their disposal (Guinée, 2001), whereas EIO provides an approach to estimate the carbon footprint from EPIs (Finnveden et al., 2009). These methods individually are not holistic and, therefore, are required to be combined to sufficiently assess the environmental impact of products and services (Finnveden et al., 2009). Neither, however, provides a way to measure and manage the environmental impacts of business operations. Yet, organizations adopt process-oriented approaches, where a 'process' is a sequence of activities, events and decisions that directly or indirectly deliver value to the organization (Dumas et al., 2013), to manage the performance of their operations (Kohlbacher \& Reijers, 2013) and align their operations with organizational strategies and culture.

\subsection{Environmental Sustainability and BPM}

BPM is well-placed to address ES management challenges because it focuses on improving organizational efficiency (Rehan et al., 2018) and operational effectiveness (Hammer, 2010), by optimizing processes, technology use, reducing waste and improving performance (Rosemann \& vom Brocke, 2010). It is a holistic management approach that facilitates managing operations, which enact an organization's strategy to deliver value (de Burgos Jimenez \& Céspedes Lorente, 2001; Longoni \& Cagliano, 2015), and continuously improving 
the economic sustainability of an organization, thus advancing the organization's competitive advantage (Hung, 2006). Process visualization, measurement, analysis, improvement and monitoring are core to BPM. They drive overall organizational performance and augment economic resources (Weske, 2012) and natural capital (e.g., time, cost and raw materials). Such resources become key performance indicators (KPIs). A collective and clear understanding of KPIs and process resources facilitates the measurement and analysis of process performance in organizations (Rosemann \& vom Brocke, 2015).

Operational and process management approaches, including the BPM lifecycle, are employed to measure and optimize KPIs (Kohlbacher \& Reijers, 2013; Sanders Jones \& Linderman, 2014). Improvement can therefore take on different meanings based on organizational strategies and objectives (Sanders Jones \& Linderman, 2014). For example, improvement could bring reduced costs and process execution time or improved quality and productivity, or reduction of environmental impact. In the ES context, EPIs of organizational processes can be measured through a BPM approach to reduce the environmental impact of organizational activities (Parmenter, 2010; Wetzstein et al., 2008). In other words, KPIs can be extended to include EPIs, and BPM analysis techniques can be applied to identify, measure, improve and monitor the environmental performance of business processes. Therefore, BPM has strong links with ES due to its process-oriented approach and facilitation of measuring and analysing EPIs at the process level (DeToro \& McCabe, 1997; Ghose et al., 2010). Such managed and controlled use of environmental resources, together with increasing organizational capabilities, ultimately results in a competitive advantage for the organization (Porter, 2008; Porter \& Van der Linde, 1995; Schmidheiny, 1992).

\section{Related work}

Stolze et al. (2012) reviewed 2006-2011 literature from English and non-English sources in the IS and BPM disciplines. They identified and categorized the literature as 'Green IT', 'Green IS', 'sustainable', and 'business process'. While the study provides high-level categories, it does not explore how BPM contributes to ES. Through examining 127 research papers, Opitz et al. (2014a) explored the potential of measuring an organization's ability to implement Green BPM. By classifying the papers according to 'attitude', 'strategy', 'governance', 'modelling', 'optimizing', and 'monitoring', these authors proposed a Green BPM readiness model motivated by the green ICT readiness model (Wabwoba et al., 2013). However, the study did not identify specific BPM concepts nor ES concepts to which contributions are made and, thus, offers a narrower focus. Subsequently, Opitz et al. (2014b) categorized the literature into 'Green IT/IS', 'BPM', 'Green BPM' as well as categories relating to 'reduce environmental impact', 'monitoring', 'economical', 'cultural change' and 'definition'. However, the extent of the theoretical contributions and details of BPM and ES concepts covered in the study is unspecified. Moreover, there is a lack of attention to EPIs which are necessary for measuring the environmental impact of organizations and monitoring performance improvement.

Maciel (2017) reviewed Green BPM literature according to six BPM components: strategic alignment, governance, method, information technology, people and culture, to extend the means to address ES and green initiatives. He found that Green BPM research literature has concentrated on BPM lifecycle steps such as design, measurement, and improving ES processes while paying little attention to strategic alignment, governance, people and culture. An initial taxonomy of sustainability in business process models was proposed by Schoormann et al. (2017), while Couckuyt (2017) focussed on the business process lifecycle in 
the Green BPM context. Couckuyt and Van Looy (2019) conducted an SLR on the contribution of BPM, operations management and IS publications to ES. The study identified the number of research studies from various disciplines, the range of environmental topics, the affiliations contributing to ES, and the types of scholarly contributions.

Our study offers a different perspective. It offers a single consolidated resource of Green BPM literature using the lens of BPM concepts, organizational factors and EPIs (Dada et al., 2013) to explain current contributions. Identifying, measuring and monitoring EPIs is crucial because organizations use them to analyse their environmental impact and monitor their performance. EPIs, if measured and reported correctly, influence an organization's strategic decisions and provide transparent and meaningful information about its environmental impact. Such data can be analysed over time to assess improvement and compliance of firms with environmental regulations and standards.

\section{Methodology}

We use a systematic literature review approach to carry out our study. We do so because an SLR assists with the identification of contributions and pinpoints research gaps related to the phenomenon under study (Kitchenham et al., 2009). SLR allows researchers to extract and evaluate the available research on a particular phenomenon of interest (Kitchenham et al., 2009) and serves as a foundation to the research in the field (Webster \& Watson, 2002). To conduct our SLR, we follow guidelines from Bandara et al. (2015) to ensure our review provides an exhaustive and comprehensive insight into BPM contributions related to ES. Because the earliest ES-related academic paper in IS was published in 2006, while research into ES in BPM prior to 2005 is non-existent, our study covers the time period of 2005 to 2019. To identify as many relevant articles as possible, we relied on Google Scholar rather than purely IS or BPM publication outlets, after identifying keywords via an initial IS and BPM data set. In addition to identifying academic papers, we identified several authoritative industry reports on ES issues and challenges to allow us to contrast industry focus with academic contributions. The search strategies for both types of contributions are outlined in the following sub-section.

\subsection{Search Strategy}

To identify search terms relevant for our study, we first explored ES-related keywords, variations and word-stems in use specifically by the IS and BPM community. We used a set of publications in prominent IS journals and high-quality conferences, because this is where most IS and BPM publications can be found. Our data set included the Association for Information Systems (AIS) senior scholars' basket of eight journals ${ }^{1}$, the Business Process Management Journal (BPMJ) and top IS and BPM conferences².

We reviewed the IS and BPM literature for frequently used ES-related keywords and identified 'Green', 'Environmentally Sustainable', 'Sustainability' and 'Sustainable', as key terms. We

\footnotetext{
${ }^{1}$ European Journal of Information Systems (EJIS), Information Systems Journal (ISJ), Information Systems Research (ISR), Journal of AIS (JAIS), Journal of Information Technology (JIT), Journal of Management Information Systems (JMIS), Journal of Strategic Information Systems (JSIS), and MIS Quarterly.

2 Pacific Asia Conference on Information Systems (PACIS), European Conference on Information Systems (ECIS), International Conference on Information Systems (ICIS), American Conference on Information Systems (AMCIS), Australasian Conference on Information Systems (ACIS), and Business Process Management Conference (BPM).
} 
also considered stemmed searches using derivations and variations of the terms 'Environmental' and 'Sustainability'. Through keeping the search terms broad and combining them with Boolean operators (see Table 1), we identified a pool of papers to analyse to identify more specific ES-related terms used by IS and BPM researchers.

\begin{tabular}{|c|c|c|}
\hline Broad BPM/IS search terms & $\begin{array}{l}\text { Boolean } \\
\text { Operators }\end{array}$ & Broad ES terms \\
\hline Information systems (IS) & \multirow[t]{6}{*}{ AND } & Environmentally sustainable \\
\hline BPM & & ES \\
\hline Business process reengineering & & Green \\
\hline (BPR) & & $\begin{array}{l}\text { Environmental, environmentally, environment*, sustainable, } \\
\text { sustainability, sustain* }\end{array}$ \\
\hline Narrow BPM/IS search terms & & Narrow ES Search terms \\
\hline Process & & $\begin{array}{l}\text { Carbon-footprint, GHG Emission, energy, ecological, } \\
\text { environmentally-aware, carbon-aware, energy-aware }\end{array}$ \\
\hline
\end{tabular}

Table 1 Search Terms and Operators

Via a manual review, we observed that some papers did not specifically mention ES in their title, yet still focused on ES (e.g. 'carbon-footprint $\left(\mathrm{CO}_{2}\right)^{\prime}$, Energy, 'GHG emission' and 'Ecological'). Therefore, we included these terms to ensure our later search using Google Scholar was inclusive. Terms such as 'environmentally-aware', 'carbon-aware', 'energyaware' were also used to identify search terms. By identifying and choosing the most-used ES terms in IS and BPM publications, we derived a list of relevant search terms (see Table 1). After identifying these terms, we combined stemmed terms to conduct searches using Google Scholar to identify publications as our primary collection of literature. We searched only articles by authors who used titles that combined our BPM and ES keywords as we considered these articles to have a central focus on ES and BPM. Then, we iteratively performed forward and backward searches, exploring bibliographic references and authors in retrieved publications.

Through this process we identified 269 journal and conference papers containing Green BPM, Green IT and Green IS contributions. By maintaining the same approach of first considering article titles, we created three categories of papers. Forty-nine publications matching ES relevant keywords and Business Process/BPM were considered to be within our Tier 1 publications. Subsequently, 122 papers with titles containing ES related terms and IS were ranked as Tier 2, while 98 papers focused on ES and IT were ranked as Tier 3 papers. We excluded Tiers 2 and 3 to maintain our focus on ES and process/BPM. Table 2 presents our criteria for including and excluding papers.

To ensure an exhaustive collection of BPM-focused articles, and assuming some IS-focused articles may contain BPM-related concepts, we double-checked excluded papers. Specifically, we conducted a full-text search for the term 'process' in the 122 Tier 2 articles, which resulted in 20 matching articles. However, because a manual review revealed none focused on BPM, they were not included in our analysis. Accordingly, using forward and backward searches, overall, we identified 49 relevant academic papers.

To ensure an exhaustive collection of BPM-focused articles, and assuming some IS-focused articles may contain BPM-related concepts, we double-checked excluded papers. Specifically, we conducted a full-text search for the term 'process' in the 122 Tier 2 articles, which resulted 
in 20 matching articles. However, because a manual review revealed none focused on BPM, they were not included in our analysis. Accordingly, using forward and backward searches, overall, we identified 49 relevant academic papers.

\begin{tabular}{|l|}
\hline \multicolumn{1}{|c|}{ Inclusion Tier and Criteria } \\
\hline Tier 1: Green BPM - articles with a focus on BPM and ES (49 papers) \\
\hline Industry reports with a focus on ES (6 reports) \\
\hline \multicolumn{1}{|c|}{ Exclusion Tier and Criteria } \\
\hline Tier 2: Green IS (122 papers) \\
\hline Tier 3: Green IT (98 papers) \\
\hline Articles did not match the inclusion criteria \\
\hline Non-English articles \\
\hline $\begin{array}{l}\text { Articles containing search terms such as BPM AND 'process' but not relevant to our focus and inclusion } \\
\text { criteria }\end{array}$ \\
\hline
\end{tabular}

\section{Table 2 Inclusions and exclusions}

To identify industry ES challenges, we performed a Google search using the keywords: 'Environmentally sustainable', 'ES' and 'Environmental Performance Indicators (EPI)'. Our resulting corpus included six authoritative agendas and annual reports. These were reports from global bodies (e.g., the United Nations [UN]), peak industry bodies and, for a local perspective, the Australian Government:

- $\quad$ The Australian Government Sustainability Plan (2010-2015) presents a plan to reduce carbon emissions and improve the sustainability of ICT operations (Commonwealth of Australia, 2010).

- $\quad$ A New Era of Sustainability: UN Global Compact - Accenture's 2010 CEO Study reports the challenges within the journey toward a sustainable economy (Lacy et al., 2010).

- $\quad$ The 2014 Annual Report by the United Nations Environment Programme (2014) highlights global development and challenges to overcome climate change and other sustainability issues.

- $\quad$ The Synthesis Report on Climate Change presents findings of three working groups that contributed to the Fifth Assessment Report (AR5) of the Intergovernmental Panel on Climate Change (IPCC): the most thorough assessment of climate change undertaken by the IPCC (2014).

- $\quad$ The Sustainable Australia Report 2013 covers emerging issues and major trends for Australia's sustainability, including ES (National Sustainability Council, 2013).

- $\quad$ ES and Industry: Road to a Sustainable Future is the largest survey of environmental practices developed from findings of the National Sustainability Council (2013). It was conducted by the Australian Industry Group in conjunction with Sustainability Victoria (Australian Industry Group, 2007).

\subsection{Coding and content analysis}

After compiling our corpus of 49 academic papers (see Appendix), we coded it to identify the significance and frequency of concepts contained within. We looked for search terms, relevant phrases, theoretical constructs and proposed research artefacts. Specifically, we looked for 
relevant BPM concepts addressed, advanced and developed, as well as any of the EPIs and ES concepts addressed, studied, tested and or implemented using process-oriented methods. To do so, we first identified a set of coding criteria, using an Excel spreadsheet.

We began with basic codes, resulting in spreadsheet columns headed, 'Title', 'Year of publication', 'Main contribution', 'BPM concept', 'Research methodology', 'Data collection method', 'Data analysis method', 'Assumptions' and 'Limitations'. In our first round of analysis, the ES and BPM specific coding criteria were based primarily on sustainability keywords identified from key papers in the sustainability literature and frequently mentioned concepts in BPM academic publications (Australian Industry Group, 2007; Epstein \& Roy, 2001; Goodland, 1995; Hammond et al., 1995; Hoesch-Klohe \& Ghose, 2012; Jasch, 2000). We based the main themes of these papers on 'types of sustainability (economic, social, environmental)', and EPIs (e.g., 'energy consumption', ' $\mathrm{CO}_{2}$ footprint', 'GHG emissions', 'waste management', 'water consumption' and 'recycling'). Similarly, we identified organizational factors related to ES and recorded them as 'management', 'strategy' and 'culture'. We classified studies about management of structure, practices, operations, and inter-organizational collaborations that support ES as 'management' factors; decision-making, and internal and external policies as 'strategy' factors; and ES organizational culture as 'culture' factors (Dada et al., 2013; Jakobi et al., 2016; Sharma, 2000; Wesumperuma et al., 2011). All 49 publications were repeatedly examined to identify the presence of the concepts mentioned above. Moreover, we identified and included literature reviews (Couckuyt \& Van Looy, 2019; Maciel, 2017; Schoormann et al., 2017; Stolze et al., 2012) in our literature set for completeness. While the EPIs and organizational factors were identified from the literature before coding the 49 articles, a set of BPM concepts (presented in section 5) emerged through consolidating the 'BPM concept' code and recoding all papers iteratively. We conducted a second round of analysis on our literature corpus to identify themes relevant to environmental impact assessment methods such as 'LCA method', 'EIO analysis', 'hybrid assessment methods', and further emerging concepts relevant to ES.

\section{Results}

Our 49-paper corpus (see Appendix) consisted of 29 conference papers, 8 journal articles and 12 book chapters published between 2005 to 2019 (see Figure 1). While the results indicate some preliminary interest in ES from BPM researchers, there was no evident trend. However, as the publication distribution suggests, ES gained more attention from BPM researchers during 2011 and 2012, due to special issues of journals and conference tracks on the topic of sustainability.

In the following subsections, we explore Green BPM research from different perspectives. First, we explore the main BPM concepts contributing to ES and relevant organizational factors. Subsequently, using the EPI focus in industry reports, we summarise Green BPM research from an EPI perspective. In addition, we explain how Green BPM research has contributed to environmental impact assessment methods, and, finally, we explore the use of theory in BPM research in the context of ES. 


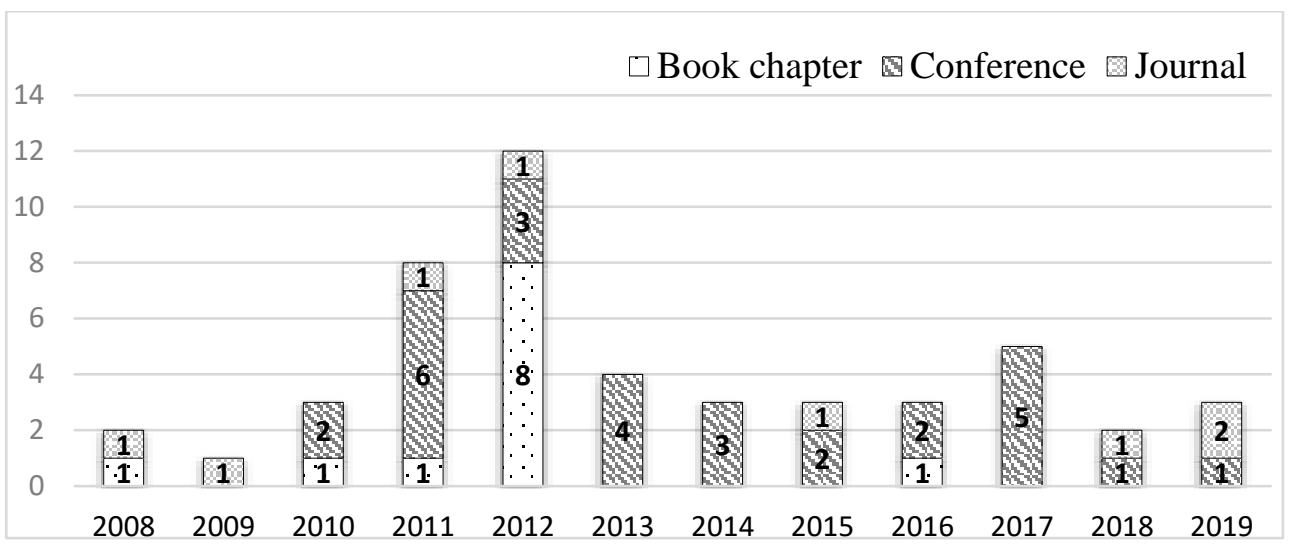

Figure 1 Distribution of publications by type per year

\subsection{Contributions of predominant BPM concepts to ES}

Through multiple iterations of reading and coding the papers, we identified nine core BPM concepts within the Green BPM literature, as follows:

'BPM lifecycle extension' suggests additional components to the current BPM lifecycle models (Rosemann \& vom Brocke, 2010; Van Der Aalst, 2004; Weske, 2012) aiming to design, analyse, model and validate business processes based on ES objectives (i.e., Green BPM Lifecycle) (Jakobi et al., 2016; Nowak, Leymann, \& Schumm, 2011; Opitz et al., 2014a; Recker et al., 2012)

'BPM architecture extension' refers to models and tools proposed to improve the business process management architecture of organizations based on targeted ES goals (Harmon, 2010; Lübbecke et al., 2016b).

'Capability maturity model extension' refers to extended theoretical dimensions for organizations to measure their current BPM maturity level based on ES as a capability (Cleven et al., 2012; Nowak, Leymann, \& Schumm, 2011; Nowak et al., 2011; Seidel et al., 2012).

'Process performance measurement method extension' refers to performance measurement methods developed and or adopted to capture environmental process performance based on EPIs (Ardagna et al., 2008; Hoesch-Klohe \& Ghose, 2010; Nowak, et al., 2011a; Recker et al., 2012; Thies et al., 2012; Wesumperuma et al., 2013).

'Process modelling extension' refers to additional modelling methods or process modelling notations to enrich process models with ES information (Hoesch-Klohe \& Ghose, 2012; Hoesch-Klohe et al., 2010; Recker et al., 2012; Wesumperuma et al., 2011).

'Process reengineering' and 'process design'3 refer to suggested techniques and methods to assist organizations in designing and reengineering (Hammer \& Champy, 1993) their business processes based on environmental objectives, e.g. reducing $\mathrm{CO}_{2}$ or GHG emissions (Ghose et al., 2010; Hoesch-Klohe \& Ghose, 2010; Lübbecke et al., 2016b; Nowak \& Leymann, 2013; Nowak et al., 2011a; Wesumperuma et al., 2013).

\footnotetext{
${ }_{3}$ Process design is concerned with creating processes to meet specific requirements inside the organization. Process reengineering is concerned with radically changing processes to maximize value in the organization, which can involve process design.
} 
'Process Optimization' (by re-designing, improving and adopting) refers to developed concepts based on iterative stages of monitoring, redesigning and improving business processes to move them towards ES organizational objectives (Ghose et al., 2010; Houy et al., 2012; Jakobi et al., 2016; Nowak \& Leymann, 2013; Pernici et al., 2008; Wesumperuma et al., 2013; Wesumperuma et al., 2011).

'Definition of Green BPM extension' includes attempts to define Green BPM based on past definitions of BPM (Weske et al., 2004) and proposed environmental performance aspects of processes (Ghose et al., 2010; Opitz et al., 2014b; Seidel \& Recker, 2012).

The top three most prominent categories of contribution from BPM to ES were through process optimization, process performance measurement methods and process design (see Figure 2). ${ }^{4}$ Several other BPM concepts were also featured, as per Figure 2. For example, twenty-four per cent of the examined papers have contributed to the BPM lifecycle and $12 \%$ to definition extension (most being conceptual studies). In the following subsections we provide a summary of these research contributions.

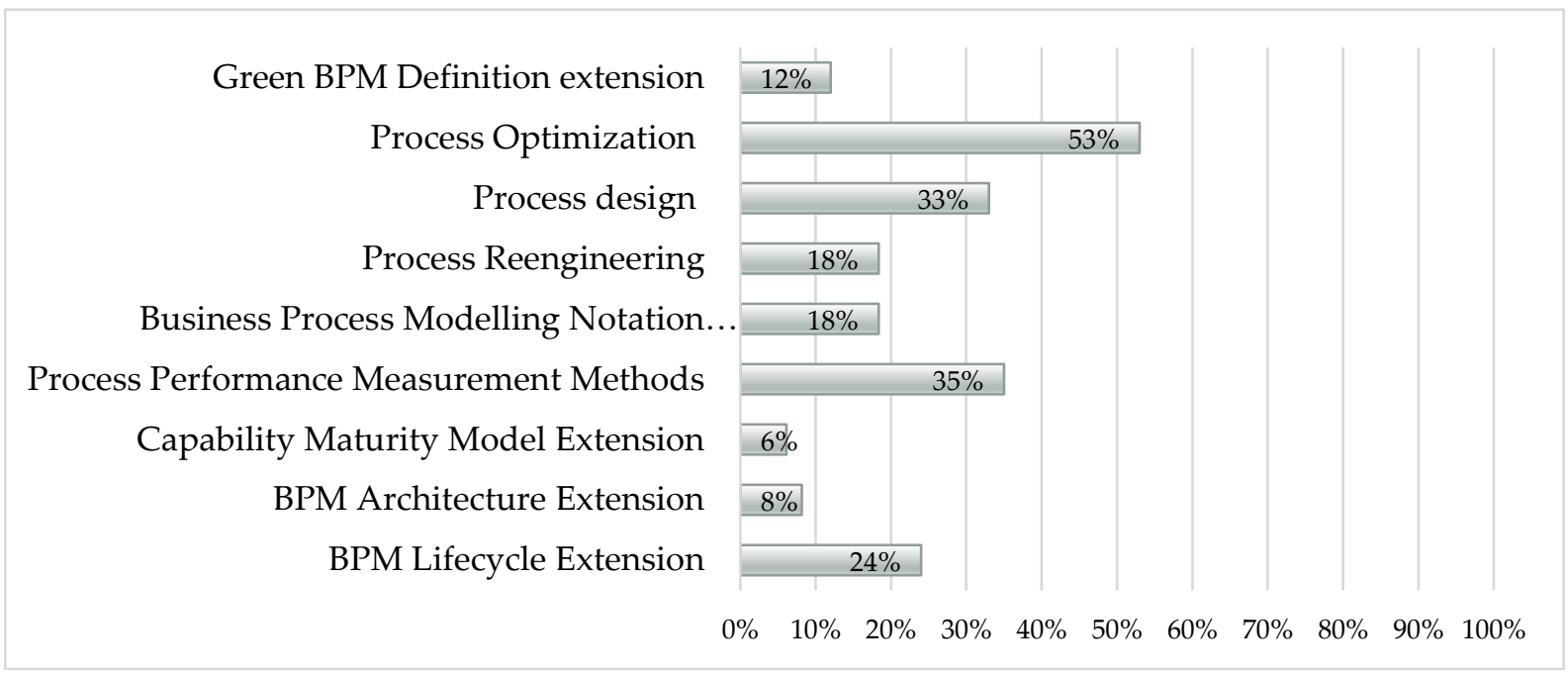

Figure 2 Relevant BPM Concepts

\subsubsection{Process optimization}

Context-aware approaches have been suggested to optimize the use of operational resources (Pernici et al., 2008). A context-aware approach increases the capability of an IS to react dynamically to operating conditions and, therefore, improves the use of resources with minimum energy consumption. Further approaches have been explored in the context of defining and measuring ecological characteristics of processes (Nowak and Leymann, 2013; Wesumperuma et al., 2011) and to do so, the concept of key ecological indicators (the same as EPIs) was suggested by Nowak et al. (2011). Furthermore, the requirement for a multidimensional framework for business process optimization was identified by Wesumperuma et al. (2011). The framework demonstrated how modelling, measuring, analysing and optimizing business processes supports the mitigation of GHG emissions from

\footnotetext{
${ }^{4}$ Twenty-eight papers had multiple contributions in terms of BPM concepts, therefore, we have coded
} the authors and their contributions through different lenses. 
business processes. Although the proposed framework was not implemented at the time of the study and therefore was not validated, the study was extended to investigate further methods to optimize GHG emissions of processes and to develop green activity-based management (ABM) (Wesumperuma et al., 2013). Green ABM merges activity-based costing $(\mathrm{ABC})$ and the critical path method (CPM) and proposes the use of environmental metrics such as GHG emissions in the same manner as businesses use process performance metrics such as time and cost in regard to processes. Accordingly, a green ABM approach provides an opportunity for organizations to include green objectives in their business performance objectives and thus adopt multi-dimensional process optimization.

To further align green initiatives with business and process objectives, the concept of 'collaborative Green BPM' was introduced, which enables stakeholder involvement in organisational sustainability initiatives (Jakobi et al., 2016). Similarly, to minimize the environmental impacts of processes, a theoretical roadmap for a carbon modelling framework was proposed by Ghose et al. (2010). Its aim is to reflect the carbon footprint of process activities, so the carbon footprint of processes becomes visible and can be easily communicated to stakeholders. Furthermore, to assist in identifying and reducing the environmental impact of processes, an ecological workflow pattern was developed to optimize green business processes (Lübbecke et al., 2016b). This approach provided decision analytics support for operations, control flow and data. The study was extended to explore further ecological process optimizations through compliance checking (Lübbecke et al., 2017) and suggested process pattern checking (Lübbecke et al., 2017; Lübbecke et al., 2018) as a method to categorize processes based on design patterns. The study extended the application of a compliance checking method by identifying ecological weaknesses and ultimately optimizing business processes.

\subsubsection{Process performance measurement methods}

Research extending 'process performance measurement methods' has generally focused on the EPIs of ' $\mathrm{CO}_{2}$ footprint', 'energy consumption' and 'GHG emissions' (Ardagna et al., 2008; Cleven et al., 2012; Hoesch-Klohe \& Ghose, 2010; Hoesch-Klohe et al., 2010; Lübbecke et al., 2016b; Recker et al., 2012; Thies et al., 2012; Wesumperuma et al., 2013). The earliest theoretical framework for an active energy-aware resource management mechanism suggested the development of process-based applications that offer high performance, are energy efficient and also measure energy consumption (Ardagna et al., 2008). A multidimensional quality of service (QoS) measurement approach for measuring the emissions of processes was also suggested using an algebraic structure of c-semiring, aiming to measure the carbon footprint of processes (Hoesch-Klohe \& Ghose, 2010). The study suggested the Abnoba framework to measure the heterogeneous environmental impacts of activities in processes. Wesumperuma (2015) expanded on earlier studies (Wesumperuma et al., 2013; Wesumperuma et al., 2011) to develop an activity-based reporting tool that creates, calculates and includes a GHG emissions inventory from activities undertaken at the business-process level. In addition, a method with a focus on process performance measurement was proposed (Cappiello et al., 2013), to improve measurement indicators such as energy consumption, $\mathrm{CO}_{2}$ emissions, and process performance requirements, measured by suitable metrics. The study used a virtual machine to test the approach in regard to improving performance while maintaining energy efficiency. 


\subsubsection{Process design and reengineering}

Process design has been explored in several studies. A conceptual study explored the benefits of service-oriented process design (Pernici et al., 2008) to achieve sustainability objectives in organisations. Based on the same concept, and to improve the environmental impact in organizations, Nowak et al. (2011b) identified frequently used process design patterns. The study focuses on organizational factors of ES, such as management. Further research related to design patterns classified green process design patterns and described the connection of the design with services, artefacts and applications (Nowak et al., 2012). Later, the study was extended (Nowak \& Leymann, 2013) to assist organizational stakeholders in identifying sustainable patterns and designing environmentally aware business processes.

Ecological (green) business process patterns were further analysed using general and specific recurring green patterns in German public sector administration (Lübbecke et al., 2016a). The study was extended with guidelines to model and design ecology-aware (green) processes (Lübbecke et al., 2017). However, both studies are ongoing, and the results are based on synthetic scenarios.

\subsubsection{BPM lifecycle and Green BPM definition extension}

The need to extend the BPM lifecycle into a 'Green BPM lifecycle' was identified by Seidel et al. (2011). By reviewing ES in the context of IT and IS literature, the study explored how IT could enable organizations to make sustainability transparent in their processes. A range of enablers of, and barriers to, adopting such processes in operations were identified through this research. Consequently, the study suggested that organizations require green initiatives, capabilities and motivators as a means of encouragement to include sustainability in their operations and to enable them to provide sustainable IT and IS solutions to their customers. To this end, the authors proposed the Green BPM lifecycle. Further, Seidel et al. (2012) emphasized the central role BPM plays in creating environmentally sustainable practices and argued that business and IT managers should provide a process-centred environment and opportunities for understanding organizational processes. The study further developed a framework for Green BPM research by exploring opportunities and contributions that BPM can offer in the context of ES.

Focusing on phases of the BPM lifecycle, the influence of Green BPM was examined in the Malaysian manufacturing sector (Kuppusamy \& Gharleghi, 2015). With a specific focus on green-supplier selection, monitoring and collaboration, the study found that green-supplier monitoring and management significantly improves the greening processes in the manufacturing sector. They also defined Green BPM differently to Seidel et al. (2012) and Opitz et al. (2014b), as a factory's institutionalization of internal environmental management practices that includes process design such that environmental impacts are reduced.

\subsubsection{Process modelling notation extension}

A process modelling notation was suggested to reflect the relationship between resources and activities (Hoesch-Klohe et al., 2010) in a study that illustrated how the measurement and modelling method could be used to improve the environmental impact of business processes. Similarly, several studies suggested various modelling methods that could be used to represent the environmental impact of business processes (Lübbecke et al., 2017; Lübbecke et al., 2018; Schoormann et al., 2017). A process modelling notation to allow for the representation of the carbon footprint of a business process was also developed by Recker et al. (2012). 
Furthermore, an emissions modelling and reporting method for $\mathrm{CO}_{2}$ and $\mathrm{GHG}$ emissions was proposed by Wesumperuma et al. (2013).

\subsubsection{BPM architecture and capability maturity model extension}

A capability maturity model that enables organizations to define and control their corporate sustainability is one of the contributions within this category. The model, based on a BPM capability model, integrates ES into the regular BPM capability of the organization and helps employees to understand the current performance and targets for future improvements in different areas, including ES (Seidel et al., 2012; Cleven et al., 2012). Capability maturity enables organizations to define, implement and monitor their sustainability efforts, based on a BPM capabilities model (de Bruin \& Rosemann, 2007).

\subsection{Organizational factors in Green BPM research}

Organizational factors include management, strategy and culture, all of which are essential in achieving ES (Wesumperuma et al., 2011). We found 45 per cent of the analysed articles acknowledged the significance of organizational perspectives by using BPM to develop conceptual frameworks and models that involved organizational perspectives (see Figure 3). Contributions to these areas in the current body of Green BPM literature are outlined below.

\subsubsection{Management}

The main ES focus, from an organizational perspective, of our 49-paper research corpus was the overarching concept of 'management'. We identified organizational structures, practices, operations and inter-organizational collaborations as key factors that support ES. Management also encompasses decision-making in internal and external policies and overlaps with 'strategy' factors; and 'culture' factors (Dada et al., 2013; Sharma, 2000; Wesumperuma et al., 2011).

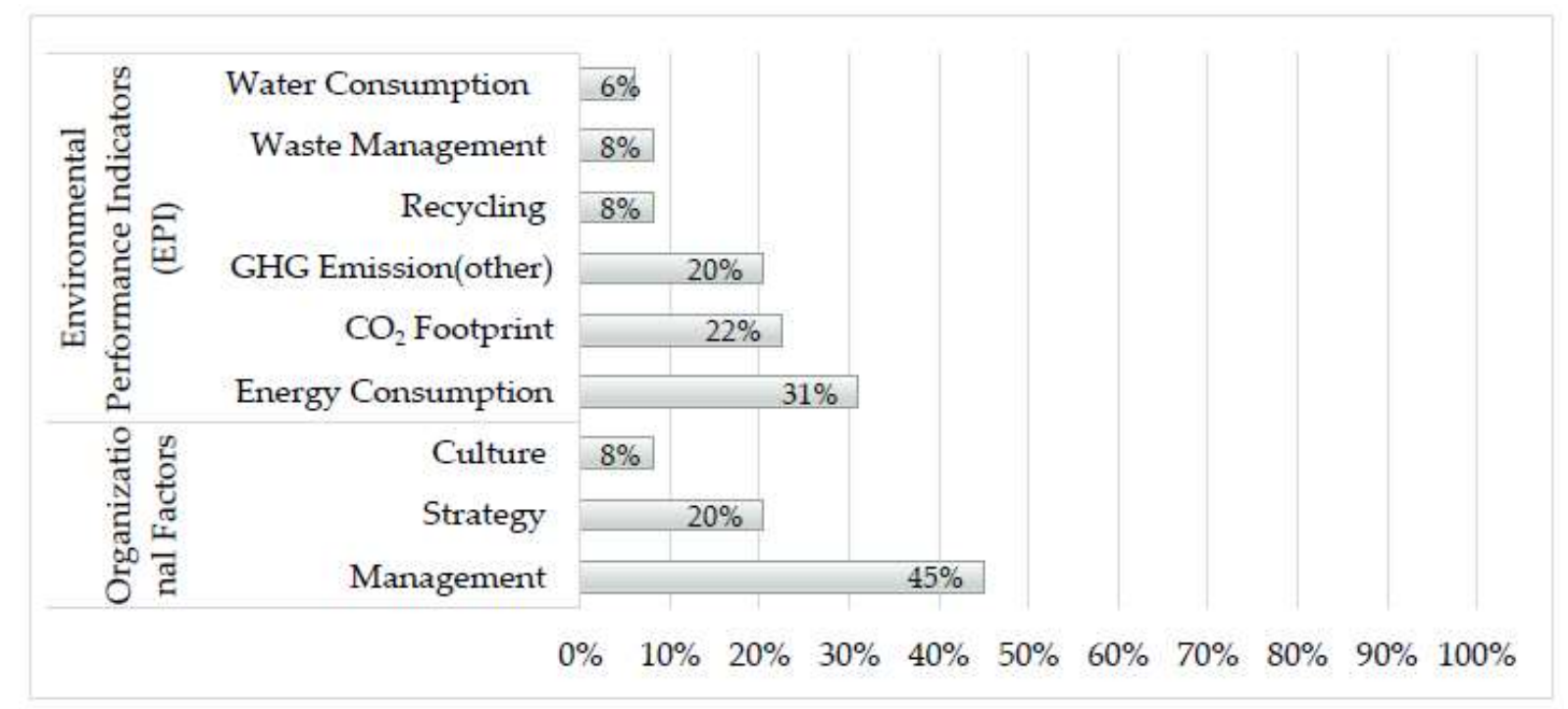

Figure 3 EPIs and relevant organizational factors

\subsubsection{Strategy and culture}

Organizational strategy and culture influence an organization's environmental performance (Dada et al., 2013; Epstein \& Roy, 2001; González-Benito \& González-Benito, 2006; Sharma, 
2000). Thus, to positively affect environmental performance, new values need to be implemented at all levels of the organizational structure and novel strategies need to be planned and regulated by national and international bodies (Lacy et al., 2010).

\subsection{EPI focus in industry versus Green BPM research}

In addition to analysing academic articles, we reviewed six reports from global institutions such as the UN, large industry bodies and the Australian Government. Table 3 shows the industry reports consistently focus on nearly all of the EPIs and organizational factors. The Commonwealth of Australia (2010) has set mandatory environmental standards for energy consumption (i.e., the ISO14001 standard family) for the ICT sector to which organizations must comply by resource recovery and recycling of material (e.g., digital devices). The IPCC (2014) addressed the challenges of climate change and provided a future pathway for adaptation, risk mitigation and sustainable development according to EPIs. Indeed, industry is expected to reduce the environmental impact of its activities in all its sectors, as per the Paris Climate Change Agreement (Harvey, 2015; Morgan et al., 2014; Rogelj et al., 2016).

\begin{tabular}{|c|c|c|c|c|c|c|c|c|c|}
\hline \multirow[b]{2}{*}{ Reports } & \multicolumn{3}{|c|}{ Organizational Factors } & \multicolumn{6}{|c|}{ Environmental Performance Indicators (EPI) } \\
\hline & 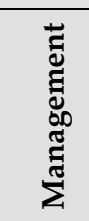 & 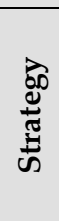 & $\frac{\dddot{\Xi}}{3}$ & 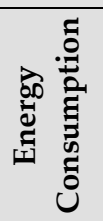 & 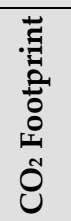 & 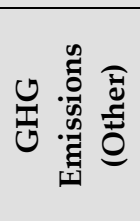 & 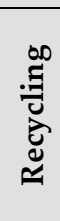 & 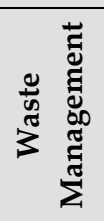 & 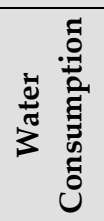 \\
\hline $\begin{array}{l}\text { (Commonwealth of } \\
\text { Australia, 2010) }\end{array}$ & $\mathscr{V}$ & $\mathscr{V}$ & $x$ & $\mathscr{V}$ & $\mathscr{V}$ & $\mathscr{\vartheta}$ & 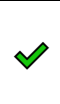 & $\mathscr{V}$ & $\mathscr{\vartheta}$ \\
\hline (Lacy et al., 2010) & $\checkmark$ & $\mathscr{q}$ & $\mathscr{q}$ & $\checkmark$ & $\mathscr{V}$ & $\mathscr{q}$ & $\checkmark$ & $\checkmark$ & $\checkmark$ \\
\hline $\begin{array}{l}\text { (United Nations } \\
\text { Environment } \\
\text { Programme, 2014) }\end{array}$ & 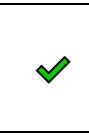 & $\mathscr{q}$ & $\mathscr{\vartheta}$ & $\mathscr{V}$ & $\mathscr{q}$ & $\mathscr{q}$ & $x$ & $\mathscr{V}$ & $\mathscr{V}$ \\
\hline (IPCC, 2014) & $\mathscr{V}$ & $\mathscr{\vartheta}$ & $\mathscr{V}$ & $\mathscr{V}$ & $\mathscr{q}$ & $\mathscr{\vartheta}$ & $\vartheta$ & $\mathscr{V}$ & $\mathscr{V}$ \\
\hline $\begin{array}{l}\text { (National Sustainability } \\
\text { Council, 2013) }\end{array}$ & $x$ & $\mathscr{q}$ & $\mathscr{V}$ & $\mathscr{V}$ & $\mathscr{q}$ & $\checkmark$ & $\checkmark$ & $\mathscr{V}$ & $\mathscr{V}$ \\
\hline $\begin{array}{l}\text { (Australian Industry } \\
\text { Group, 2007) }\end{array}$ & $\mathscr{V}$ & $\checkmark$ & $\checkmark$ & $\checkmark$ & $\checkmark$ & $\checkmark$ & $\checkmark$ & $\mathscr{V}$ & $\checkmark$ \\
\hline
\end{tabular}

Table 3 Focus of industry reports by ES organizational factors and EPIs

Energy consumption is a main agenda of all of our six identified industry/government reports, including the United Nations Environment Programme (2014) and the ICT Sustainability Plan by the Commonwealth of Australia (2010). An environmental management strategy is required to audit and control energy consumption. Of the 49 identified research articles, 15 (i.e., 31\%) contain contributions to energy consumption management. From these 15, 14 are conceptual in nature and focus on energy-aware applications to reduce energy consumption (Ardagna et al., 2008), purifier-based approaches (Pernici et al., 2008), a case study on networkcentric solutions (Thies et al., 2012), applying an algebraic framework to multiple heterogeneous dimensions (Hoesch-Klohe \& Ghose, 2012), process improvement methods to support measuring and monitoring performance and energy efficiency, and a conceptual integration model for energy consumption from IT components to business processes (Reiter et al., 2014). Energy consumption and waste in processes can be reduced by applying 
techniques and solutions from BPM (Houy et al., 2011). Furthermore, energy consumption feedback systems can change organizational behaviour in relation to energy consumption (Jakobi et al., 2016).

$\mathrm{CO}_{2}$ and GHG emissions directly influence climate change (IPCC, 2014; Young \& Rikhardsson, 1996). From 1970 to 2010, $\mathrm{CO}_{2}$ emissions from fossil fuels and industrial processes contributed 78 per cent of the total worldwide GHG accumulation (IPCC, 2014). Continued emissions of high levels of $\mathrm{CO}_{2}$ and GHG will increase the possibility of pervasive, severe impacts on the population and the ecosystem by increasing surface and ocean temperatures (IPCC, 2014). The United Nations Environment Programme (2014) produced a roadmap for cutting emissions because costs of climate change adaptation will reach $\$ 300$ billion per year by 2050. The concern about climate change from GHG emissions also continues to grow (Lacy et al., 2010). Of the 49 BPM research articles, 11 articles (22\%) focus on measuring and managing $\mathrm{CO}_{2}$ emissions. These contributions, which are mostly conceptual in nature, include a framework for carbon-aware process improvement (Hoesch-Klohe \& Ghose, 2012), a roadmap to optimize the carbon modelling framework (Ghose et al., 2010), activity-based emissions analysis for measuring $\mathrm{CO}_{2}$ in processes (including a modelling notation extension, specifically BPMN) (Recker et al., 2011; Recker et al., 2012), network centric solutions (Thies et al., 2012), conceptual advancement of methods for measuring and monitoring process performance based on EPIs such as $\mathrm{CO}_{2}$ (Cappiello et al., 2013) and theoretical principles for capturing, measuring, modelling and reporting $\mathrm{CO}_{2}$ and GHG emissions (Wesumperuma et al., 2013). A process-based method was proposed by Ghose et al. (2010) to measure emissions from business processes. The method uses three scopes: 1) direct emissions that occur from internal activities in an organization; 2) indirect emissions from sources external to the organization; and 3) all other indirect emissions not part of scope two which are material emissions, employee commuting emissions etc. Based on this approach, there are three types of resources, atomic, shared resources and hybrid resources, which organizations need to consider while measuring the carbon footprint and GHG emissions of their activities. The paper provides a roadmap for carbon-aware BPM. The studies focusing on $\mathrm{CO}_{2}$ footprint and GHG emissions are mainly conceptual.

Recycling, waste management and water consumption have received less focus from the BPM research community. Of the 49 publications studied, four focus on waste management, with recycling and water consumption having three related articles each. Hoesch-Klohe and Ghose (2010) discussed the potential of extended EPIs in the application of the Abnoba Algebraic framework for process optimization. The authors presented a conceptual framework for the green quality of service measures that generalizes qualitative and quantitative scales and permits the integration of multiple heterogeneous measures into a single composite scale. As a result, the framework can measure 'water consumption', ' $\mathrm{CO}_{2}$ emissions' and 'waste generation', which are mainly quantifiable, and 'damage to fauna and flora', which is qualitative. Combined measures such as 'air quality' and 'environmental performance' could be heterogeneously measured together. Thus, while the main global and industry reports indicate the significance of these three EPIs in achieving ES (Australian and New Zealand Environment and Conservation Council State of the Environment Reporting Task Force, 2000; Australian Industry Group, 2007; Commonwealth of Australia, 2010; IPCC, 2014; United Nations Environment Programme, 2014), a substantial response from the BPM literature is yet to come. Again, most of the studies are conceptual with the three EPIs being narrowly discussed. 
Table 4 summarizes the number of articles that contribute to an EPI through a specific BPM concept. For each BPM concept, it also shows the contributions to relevant organizational factors, and the overall number of research papers that have focused on that particular BPM concept.

\begin{tabular}{|c|c|c|c|c|c|c|c|c|c|c|}
\hline \multirow[b]{2}{*}{ BPM Concepts } & \multicolumn{3}{|c|}{$\begin{array}{l}\text { Organizational } \\
\text { factors }\end{array}$} & \multicolumn{6}{|c|}{ Environmental performance indicators (EPI) } & \multirow[b]{2}{*}{ 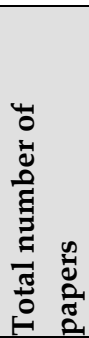 } \\
\hline & 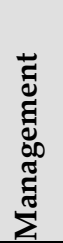 & $\begin{array}{l}\overrightarrow{0} \\
\text { 节 } \\
\omega\end{array}$ & 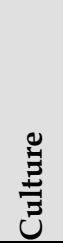 & 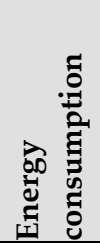 & 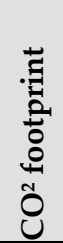 & 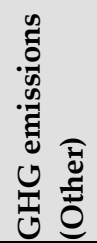 & 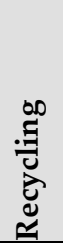 & 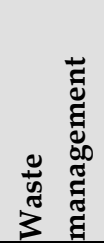 & 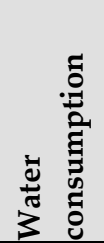 & \\
\hline BPM Lifecycle Extension & 5 & 4 & 2 & 1 & 3 & 1 & - & 1 & - & 12 \\
\hline BPM Architecture Extension & 2 & 2 & 1 & 1 & - & - & - & - & - & 4 \\
\hline $\begin{array}{l}\text { Capability Maturity Model } \\
\text { Extension }\end{array}$ & 3 & 2 & 1 & - & - & - & - & - & - & 3 \\
\hline $\begin{array}{l}\text { Process Performance } \\
\text { Measurement Extension }\end{array}$ & 6 & 3 & 1 & 6 & 6 & 5 & 2 & 2 & 2 & 17 \\
\hline Process Modelling Extension & 3 & 1 & 1 & 1 & 4 & 2 & 1 & - & - & 9 \\
\hline $\begin{array}{l}\text { Business Process } \\
\text { Reengineering }\end{array}$ & 4 & 2 & - & 3 & 1 & 2 & 1 & 1 & 1 & 9 \\
\hline Process Design & 6 & 2 & 1 & 6 & 5 & 4 & 2 & 2 & 2 & 16 \\
\hline Process Optimization & 11 & 5 & 2 & 8 & 7 & 7 & 1 & 1 & 1 & 26 \\
\hline $\begin{array}{l}\text { Green BPM definition } \\
\text { extension }\end{array}$ & 3 & 2 & 1 & - & - & - & - & - & - & 6 \\
\hline
\end{tabular}

Table 4 BPM concepts contributing to ES organizational factors and EPIs

\subsection{Contribution to environmental impact assessment methods}

Several articles have contributed to assessing the environmental impact of processes using existing impact assessment techniques applied to products, services and operations such as lifecycle assessment (LCA), input-output analysis (EIO) or resource-based analysis.

Process-analysis techniques for activity-based costing were adapted by Recker et al. (2011) to measure the environmental emissions of processes under the title of activity-based emissions. The authors also discussed three diverse methods to measure $\mathrm{CO}_{2}$ emissions from business processes: bottom-up, which is the same as process-based analysis; top-down, which is the analysis of inputs and outputs of processes or products; and a hybrid or combined method that uses a combination of the two other methods. They calculated $\mathrm{CO}_{2}$ emissions on an exploratory case of a direct invoicing process in an organization. Later, Recker et al. (2012) proposed an approach to modelling and recording the carbon footprints of business processes. Using a business process model example and an extended activity-based costing example, the authors presented a process-based perspective of modelling and analysing $\mathrm{CO}_{2}$ emissions from business processes. An extension to process modelling was suggested which allows better communication and monitors the compliance and recording of environmental information about processes. Example case studies were used to demonstrate the practicality of conducting an activity- and process-based measurement of environmental emissions from business processes. 
With a focus on identifying the environmental impact of activities, Hoesch-Klohe and Ghose (2012) reviewed suggested potential BPM contributions to ES in organizations. The authors noted that the environmental impact of activities and processes could be identified using a variety of different methods (e.g., educated guess by experts, activity-based costing, and derivation from resource model and carbon-dioxide accumulation). They used case studies to demonstrate a trade-off analysis for environmentally aware business process design and a framework for green process improvement.

Regarding bottom-up impact assessment, Wesumperuma et al. (2013) proposed a green activity-based management (ABM) approach to measure, report and manage environmentally sustainable business processes. This study was later extended by Wesumperuma (2015) to develop an activity-based reporting tool which creates, calculates and incorporates a GHG emissions inventory of activities at the business-process levels.

\subsection{Use of theory in Green BPM research}

Academic literature should develop, test and use theories; this applies in the IS field (Gregor, 2006) as well as in the BPM fields and sets academic publications apart from practitioner and consultant reports. Therefore, we also reviewed the literature to identify examples of theory building. Of the 49 publications we analysed, five applied theories to their studies and two theorized models using case studies, but none attempted to extend previously developed theories.

Ardagna et al. (2008) applied systems and control theory and queuing theory (Qin \& Wang, 2007) to their framework for active energy-aware management of business processes. Whereas, Cleven et al. (2012) used Socio-Technical theory (Bostrom \& Heinen, 1977) to understand the different components, systems and sub-systems in organizations that should be considered to understand, measure and manage the impact of IS activities on the environment. To develop energy-aware and optimized processes, Cappiello et al. (2013) used a multiple criteria decision-making theory (Triantaphyllou, 2000). Furthermore, to highlight the benefits to companies for adopting environmentally sustainable practices, Kuppusamy and Gharleghi (2015) used RBV theory (Barney, 1991) to study the competitive advantage companies can gain by applying their valuable resources to sustainable practices. Finally, considering the role of the consumer, Jakobi et al. (2016) explained that rational choice theory (Jackson, 2005) and value belief norm theory (Stern et al., 1999) support feedback campaigns for change in consumer behaviour to reduce energy consumption.

A case study on the adoption of environmentally sustainable practices conducted by Seidel et al. (2010) recognized that IT can enable sustainable operations. Their study also encouraged future research to investigate the adoption of sustainable practices to develop a more generalized view and theoretical models. Also based on case studies, Seidel and Recker (2012) developed a framework to theorize sustainable business process implementation.

\section{Green BPM: The next steps}

Our analysis of global industry reports reflects an increasing understanding of organizational factors and EPIs related to ES (see Table 3). By using various BPM concepts, we propose several research directions within the BPM and ES context, as outlined below.

Several studies focused on management and strategy within organizations have recommended extending the BPM lifecycle into a Green BPM lifecycle. BPM is often referred 
to as a holistic management approach in managing an organization's performance; therefore, naturally, it should also focus on the cultural, strategic and management success factors, and complexities of continual process improvement to achieve ES throughout Green BPM lifecycle phases. Future Green BPM research should involve designing, evaluating, implementing and monitoring environmentally sustainable processes that meet the ES strategies for all EPIs.

Further, while Green BPM literature has generated knowledge about organizational aspects of environmentally sustainable BPM, successful adoption and sustainable solutions that include economic and social sustainability should also be explored in more depth. Consequently, critical success factors for Green BPM should be explored.

BPM architecture studies have not considered EPIs specifically, yet the need exists for researchers to consider further dimensions of BPM architecture that address EPIs and combine processes, practices and structure of organizations into a capability model. A capability model should include environmentally sustainable practices, strategies and governance that guides the targets and assessment and improvement of green capability maturity of organizations. A green capability maturity model would enable organizations to identify, assess and improve their practices, processes and strategies with regards to their ES objectives. Such research into suitable capability maturity models that address specific EPIs is restricted even though the extent of the overlap of the capabilities related to managing specific EPIs is clear.

More than any other BPM concept, a considerable number of studies have focussed on measuring process performance. Several studies explore methods to measure and manage EPIs using energy consumption and $\mathrm{CO}_{2}$ and GHG emissions. While some evidence exists of suitable measurement methods for other EPIs (e.g., recycling, water consumption and waste management), most research is conceptual in nature and lacks further evidence of how to apply measures successfully and correctly. Further study is required to identify the right EPIs and techniques to measure the impact in organizations. To support industry to reduce climate change, we see a need for studies focused on implementing EPI measurement methods, organizational planning, and changing organizational procedures as well as changing organizational culture to address the management of all EPIs, to provide guidance to organisations.

Several researchers have suggested extending process modelling notations to reflect EPIs such as $\mathrm{CO}_{2}$ footprint and GHG emissions in process models. Future research should explore whether and what ES information would be useful to visualise in business process models in practice, whether they also apply to other EPIs and, ultimately, whether they enable better management/awareness of EPIs in the long run.

We suggest further research in identifying the success factors of environmentally sustainable process design, reengineering and optimization. Stolze et al. (2012) and Thies et al. (2012) provide an initial study of success factors related to implementing environmentally sustainable processes. However, design, adoption and implementation of ES in organizations incurs a cost and requires significant change (Adger et al., 2005; Christmann, 2000), thus it is important that studies identify and empirically validate related success factors. We particularly note a lack of studies that focus on adopting green practices and processes without compromising organizational and process competence.

In general, we also see a lack of research into the cultural factors underlying BPM and ES (see Table 4). While benefits can be achieved from applying BPM initiatives because of the 
incremental improvement approach they take and their holistic view of people and systems (Pritchard \& Armistead, 1999; vom Brocke \& Sinnl, 2011), adopting ES requires a culture change by organizations (Harris \& Crane, 2002). Culture change may be achieved through reflecting on the environmental impact of individual behaviour in organizations; also, by democratizing information and holding discussions with individuals (Degirmenci \& Recker, 2018). Green or eco nudging has also been shown to influence individual behaviour and overall practices in organizations (Hall, 2013). However, changing any practice in organizations requires continual improvement (Gao \& Low, 2014). Therefore, change in organizational practices and individual behaviour towards ES requires raising public and individual awareness about the impact of climate change, together with offering practical solutions to individuals (Linnenluecke \& Griffiths, 2010; Nerlich et al., 2010). Future studies could consider the effect of increasing individual ES awareness, perhaps via games, apps and/or devices, to raise awareness of specific EPIs. For example, gamification has received recent academic attention (Hamari et al., 2014; Schlagenhaufer \& Amberg, 2015) yet its value in the context of ES, by changing individuals' awareness of ES and their behaviour, is unknown.

\section{Conclusion}

In this study, we conducted a systematic review of Green BPM literature to identify relevant contributions to environmental sustainability, with a specific lens on EPIs and relevant organizational factors. To this end, we identified, collected and analysed 49 relevant academic research articles. Our analysis identified the core BPM contributions, viz., BPM Lifecycle Extension, BPM Architecture Extension, Capability Maturity Model Extension, Process Performance Measurement Extension, Process Modelling Extension, Business Process Reengineering, Process Design, Process Optimization, Green BPM definition extension, with the main ones being Process Optimization, Process Performance Measurement Methods and Process Design. We also identified Green BPM literature's most researched EPIs as energy consumption, $\mathrm{CO}_{2}$ emissions and GHG emission and summarised Green BPM contributions through the EPI lens. Further, we presented Green BPM contributions from the perspective of environmental impact assessment methods, and, finally, considered the use of theory underlying Green BPM research. As a result of our analysis, we identified future research directions related to the core BPM concepts identified.

Our literature review is not without limitations. While papers were collected and identified by one researcher and checked by another, coding of the papers to BPM and ES was done by one researcher. Despite the coding being conducted using multiple iterations of full readings of relevant papers, having a single coder remains a shortcoming that might introduce bias in the analysis. In addition, while we strived to consider the largest set of relevant papers possible, our focus was on contributions published in English only. Our search also resulted in some green supply chain management (SCM) articles. While 'process' is a common term in SCM, because none of the articles we found explicitly focused on Green BPM we excluded green SCM from this study, which presents a limitation in scope.

\section{References}

Adger, W. N., Arnell, N. W., \& Tompkins, E. L. (2005). Successful adaptation to climate change across scales. Global environmental change, 15(2), 77-86. 
Applegate, L. M., \& King, J. L. (1999). Rigor and relevance: careers on the line. Management Information Systems Quarterly, 23, 17-18.

Ardagna, D., Cappiello, C., Lovera, M., Pernici, B., \& Tanelli, M. (2008). Active energy-aware management of business-process based applications: Springer.

Australian and New Zealand Environment and Conservation Council State of the Environment Reporting Task Force. (2000). Core environmental indicators for reporting on the state of the environment. Retrieved from www.environment.gov.au/system/files/pages/-a94a73f8-79db-4347-8a7af03ecdc48074/files/core-indicators.pdf

Australian Industry Group. (2007). Environmental Sustainability and Industry: Road to a sustainable future - Findings of the National Survey on Environmental Sustainable Practices. Sustainability Victoria, Melbourne

Bandara, W., Furtmueller, E., Gorbacheva, E., Miskon, S., \& Beekhuyzen, J. (2015). Achieving Rigour in Literature Reviews: Insights from Qualitative Data Analysis and Tool-support. Communications of the Association for Information Systems, 37(1), 8.

Bansal, P., \& Roth, K. (2000). Why companies go green: A model of ecological responsiveness. Academy of management journal, 43(4), 717-736.

Barney, J. (1991). Firm resources and sustained competitive advantage. Journal of Management, 17(1), 99-120.

Blohm, I., \& Leimeister, J. M. (2013). Gamification: Design of IT-Based Enhancing Services for Motivational Support and Behavioral Change. Business $\mathcal{E}$ Information Systems Engineering, Volume 5(4), 275-278. doi:10.1007/s12599-013-0273-5

Bostrom, R. P., \& Heinen, J. S. (1977). MIS problems and failures: a socio-technical perspective, part II: the application of socio-technical theory. MIS Quarterly, 11-28.

British Standards Institution. (1994). Specification for Environmental Management Systems. Retrieved from https://shop.bsigroup.com/ProductDetail/?pid=000000000000322818

Brooks, S., Wang, X., \& Sarker, S. (2012). Unpacking Green IS: A Review of the Existing Literature and Directions for the Future. In J. vom Brocke, S. Seidel, \& J. Recker (Eds.), Green Business Process Management (pp. 15-37): Springer Berlin Heidelberg.

Brown, B., Hanson, M., Liverman, D., \& Merideth, R., Jr. (1987). Global sustainability: Toward definition. Environmental Management, 11(6), 713-719. doi:10.1007/BF01867238

Cappiello, C., Plebani, P., \& Vitali, M. (2013). Energy-aware process design optimization. Proceeding of the 2013 International Conference on Cloud and Green Computing (CGC), (pp. 451-458).

Chen, A. J., Watson, R. T., Boudreau, M.-C., \& Karahanna, E. (2011). An institutional perspective on the adoption of Green IS \& IT. Australasian Journal of Information Systems, $17(1)$

Cheong, C., Cheong, F., \& Filippou, J. (2013). Using Design Science Research to Incorporate Gamification into Learning Activities. Proceedings of the 2013 Pacific Asia Conference on Information Systems, Jeju Island, Korea (pp. 156-171) 
Christmann, P. (2000). Effects of "best practices" of environmental management on cost advantage: The role of complementary assets. Academy of Management Journal, 43(4), 663680 .

Cleven, A., Winter, R., \& Wortmann, F. (2012). Managing Process Performance to Enable Corporate Sustainability: A Capability Maturity Model. In J. vom Brocke, S. Seidel, \& J. Recker (Eds.), Green Business Process Management (pp. 111-129): Springer Berlin Heidelberg.

Commonwealth of Australia. (2010). Australian Government ICT sustainability plan 2010-2015 (978-1921733154). Retrieved from Canberra, A.C.T. Retrieved from https://dga.or.th/upload/download/file_bd887ff18f65ded54fe5cf7f38858446.pdf

Couckuyt, D. (2017). An Overview of Challenges and Research Avenues for Green Business Process Management. Proceedings of the OTM Confederated International Conferences" On the Move to Meaningful Internet Systems". (pp. 270-279). Springer, Cham.

Couckuyt, D., \& Van Looy, A. (2019). Green BPM as a Business-Oriented Discipline: A Systematic Mapping Study and Research Agenda. Sustainability, 11(15), 4200.

Dada, A., Stanoevska-Slabeva, K., \& Gómez, J. M. (2013). Organizations' Environmental Performance Indicators: Springer.

de Bruin, T., \& Rosemann, M. (2007). Using the Delphi technique to identify BPM capability areas. Proceedings of the 18th Australasian Conference on Information Systems, The University of Southern Queensland, Toowoomba, Australia, pp. 643-653 (2007)

de Burgos Jimenez, J., \& Céspedes Lorente, J. J. (2001). Environmental performance as an operations objective. International Journal of Operations \& Production Management, 21(12), 1553-1572.

Degirmenci, K., \& Recker, J. (2018). Creating Environmental Sensemaking through Green IS: An Experimental Study on Eco-Nudging Paper Printing Behavior. Proceedings of the Twentyfourth Americas Conference on Information Systems, New Orleans. (pp. 1- 10)

Dehghanian, F., \& Mansour, S. (2009). Designing sustainable recovery network of end-of-life products using genetic algorithm. Resources, Conservation and Recycling, 53(10), 559-570.

Deterding, S., Sicart, M., Nacke, L., O'Hara, K., \& Dixon, D. (2011). Gamification. using gamedesign elements in non-gaming contexts. Proceedings of the CHI'11 Extended Abstracts on Human Factors in Computing Systems. pp. 2425-2428

DeToro, I., \& McCabe, T. (1997). How to stay flexible and elude fads. Quality Progress, 30(3), 55.

Dumas, M., La Rosa, M., Mendling, J., \& Reijers, H. A. (2013). Introduction to Business Process Management. In Fundamentals of Business Process Management (pp. 1-31). Berlin, Heidelberg: Springer Berlin Heidelberg.

Elkington, J. (1998). Partnerships from cannibals with forks: The triple bottom line of 21stcentury business. Environmental quality management, 8(1), 37-51.

Epstein, M. J., \& Roy, M.-J. (2001). Sustainability in action: Identifying and measuring the key performance drivers. Long Range Planning, 34(5), 585-604. 
Finnveden, G., Hauschild, M. Z., Ekvall, T., Guinée, J., Heijungs, R., Hellweg, S., . . Suh, S. (2009). Recent developments in Life Cycle Assessment. Journal of Environmental Management, 91(1), 1-21. doi:https://doi.org/10.1016/j.jenvman.2009.06.018

Gao, S., \& Low, S. (2014). The Toyota Way. In Lean Construction Management (pp. 49-100): Springer Singapore.

Gholami, R., Watson, R. T., Molla, A., Hasan, H., \& Bjørn-Andersen, N. (2016). Information systems solutions for environmental sustainability: How can we do more? Journal of the Association for Information Systems, 17(8), 521.

Ghose, A., Hoesch-Klohe, K., Hinsche, L., \& Le, L.-S. (2010). Green business process management: A research agenda. Australasian Journal of Information Systems, 16(2).

González-Benito, J., \& González-Benito, Ó. (2006). A review of determinant factors of environmental proactivity. Business Strategy and the Environment, 15(2), 87-102.

Goodland, R. (1995). The Concept of Environmental Sustainability. Annual Review of Ecology and Systematics, 26, 1-24. doi:10.2307/2097196

Gregor, S. (2006). The nature of theory in information systems. MIS Quarterly, 611-642.

Guinée, J. (2001). Handbook on life cycle assessment-operational guide to the ISO standards. The international journal of life cycle assessment, 6(5), 255-255.

Hall, C. M. (2013). Framing behavioural approaches to understanding and governing sustainable tourism consumption: Beyond neoliberalism, "nudging" and "green growth"? Journal of Sustainable Tourism, 21(7), 1091-1109.

Hamari, J., \& Koivisto, J. (2013). Social Motivations To Use Gamification: An Empirical Study Of Gamifying Exercise. Proceedings of the European Conference on Information Systems (ECIS). Utrecht, The Netherlands, June 5-8, 2013.

Hamari, J., Koivisto, J., \& Sarsa, H. (2014). Does gamification work?--a literature review of empirical studies on gamification. Proceedings of the 47th Hawaii International Conference on System Sciences (HICSS), USA, January 6-9, 2014.

Hammer, M. (2010). What is business process management? In J. v. B. M. Rosemann (Ed.), Handbook on business process management: Introduction, methods and information system (Vol. 1, pp. 3-16). Berlin, Germany: Springer.

Hammer, M., \& Champy, J. (1993). Reengineering the corporation: A manifesto for business revolution. Business Horizons, 36(5), 90-91.

Hammond, A., Adriaanse, A., Rodenburg, E., Bryant, D., \& Woodward, R. (1995). Environmental indicators: a systematic approach to measuring and reporting on environmental policy performance in the context of sustainable development. Retrieved from World Resources Institute: http://pdf.wri.org/environmentalindicators_bw.pdf

Harmon, P. (2010). The scope and evolution of business process management. In Handbook on Business Process Management 1 (pp. 37-81): Springer.

Harris, L. C., \& Crane, A. (2002). The greening of organizational culture: Management views on the depth, degree and diffusion of change. Journal of Organizational Change Management, 15(3), 214-234. 
Harvey, F. (2015). Paris climate change agreement: the world's greatest diplomatic success. The Guardian, 14, 15.

Hernández González, A., Calero, C., Pérez Parra, D., \& Mancebo, J. (2019). Approaching Green BPM characterisation. Journal of Software: Evolution and Process, 31(2), e2145.

Hoesch-Klohe, K., \& Ghose, A. (2010). Carbon-Aware Business Process Design in Abnoba. In P. Maglio, M. Weske, J. Yang, \& M. Fantinato (Eds.), Service-Oriented Computing (Vol. 6470, pp. 551-556): Springer Berlin Heidelberg.

Hoesch-Klohe, K., \& Ghose, A. (2012). Environmentally Aware Business Process Improvement in the Enterprise Context. Harnessing Green IT: Principles and Practices, 265.

Hoesch-Klohe, K., Ghose, A., \& Lê, L.-S. (2010). Towards green business process management. Proceedings of the 2010 IEEE International Conference on Services Computing (pp. 386393). IEEE.

Houy, C., Reiter, M., Fettke, P., \& Loos, P. (2011). Towards Green BPM-Sustainability and resource efficiency through business process management. Proceedings of the business process management workshops 2010, LNBIP 66, Hoboken, NJ, USA (pp. 501-510).

Houy, C., Reiter, M., Fettke, P., Loos, P., Hoesch-Klohe, K., \& Ghose, A. (2012). Advancing Business Process Technology for Humanity: Opportunities and Challenges of Green BPM for Sustainable Business Activities. In J. vom Brocke, S. Seidel, \& J. Recker (Eds.), Green Business Process Management (pp. 75-92): Springer Berlin Heidelberg.

Hung, R. Y.-Y. (2006). Business process management as competitive advantage: a review and empirical study. Total Quality Management \& Business Excellence, 17(1), 21-40. doi:10.1080/14783360500249836

International Organisation for Standardization, I. (2013). The ISO Survey. Retrieved from https://www.iso.org/news/2014/09/Ref1893.html

IPCC. (2014). Climate Change 2014: Synthesis Report. Contribution of Working Groups I, II and III to the Fifth Assessment Report of the Intergovernmental Panel on Climate Change (9291691437). Retrieved from https://www.ipcc.ch/pdf/assessmentreport/ar5/syr/SYR_AR5_FINAL_full.pdf

Jackson, T. (2005). Motivating sustainable consumption. Sustainable Development Research Network, 29, 30.

Jakobi, T., Castelli, N., Nolte, A., Schönau, N., \& Stevens, G. (2016). Towards Collaborative Green Business Process Management as a Conceptual Framework. In Advances and New Trends in Environmental and Energy Informatics (pp. 275-293): Springer.

Jamous, N., \& Müller, K. (2013). Environmental Performance Indicators. In A. Dada, K. Stanoevska, \& J. M. Gómez (Eds.), Organizations' Environmental Performance Indicators (pp. 3-18): Springer Berlin Heidelberg.

Jasch, C. (2000). Environmental performance evaluation and indicators. Journal of Cleaner Production, 8(1), 79-88. doi:http://dx.doi.org/10.1016/S0959-6526(99)00235-8

Kankanhalli, A., Taher, M., Cavusoglu, H., \& Kim, S. H. (2012). Gamification: A new paradigm for online user engagement. Proceedings of the Thirty Third International Conference on Information Systems (ICIS), Orlando, FL, December 16-19, 2012, pp. 1-10. 
Kitchenham, B., Brereton, O. P., Budgen, D., Turner, M., Bailey, J., \& Linkman, S. (2009). Systematic literature reviews in software engineering-a systematic literature review. Information and software technology, 51(1), 7-15.

Kohlbacher, M., \& Reijers, H. A. (2013). The effects of process-oriented organizational design on firm performance. Business Process Management Journal, 19(2), 245-262.

Kuppusamy, M., \& Gharleghi, B. (2015). Green Business Process Management in manufacturing firms: Examining the role of upstream and downstream suppliers International Journal of Applied Business and Economic Research IJABER, 13(1), 259-271.

Lacy, P., Cooper, T., Hayward, R., \& Neuberger, L. (2010). A new era of sustainability: United Nations Global Compact-Accenture CEO Study Retrieved from https://www.comunicarseweb.com/sites/default/files/biblioteca/pdf/1321968280_334347 37-New-Era-Sustainabiltiy-Accenture-UNGC-Study-2010.pdf

Lane, M. S., Kolbe, L., \& Zarnekow, R. (2011). Editorial for special issue of AJIS on Green IT/IS (Sustainable computing). Australasian Journal of Information Systems, 17(1). doi:10.3127/ajis.v17i1.666

Linnenluecke, M. K., \& Griffiths, A. (2010). Corporate sustainability and organizational $\begin{array}{llll}\text { culture. Journal of World Business, 45(4), 366. } & \end{array}$ doi:http://dx.doi.org/10.1016/j.jwb.2009.08.006

Lintukangas, K., Kähkönen, A.-K., \& Ritala, P. (2016). Supply risks as drivers of green supply management adoption. Journal of Cleaner Production, 112, 1901-1909.

Longoni, A., \& Cagliano, R. (2015). Environmental and social sustainability priorities: Their integration in operations strategies. International Journal of Operations \& Production Management, 35(2), 216-245.

Lübbecke, P., Fettke, P., \& Loos, P. (2016a). Sustainability Patterns for the Improvement of ITRelated Business Processes with Regard to Ecological Goals. In BPM Workshops (281), M. Dumas and M. Fantinato (eds.), Cham: Springer International Publishing, pp. 428-439.

Lübbecke, P., Fettke, P., \& Loos, P. (2016b). Towards ecological workflow patterns as an instrument to optimize business processes with respect to ecological goals. Proceedings of the 49th Hawaii International Conference on System Sciences (HICSS), 1049-1058.

Lübbecke, P., Fettke, P., \& Loos, P. (2017). Towards Guidelines of Modeling for Ecology-Aware Process Design. Proceedings of the International Conference on Business Process Management. BPM Workshops, Vol. 308, Springer, Cham, pp. 510-519

Lübbecke, P., Goswami, A., \& Fettke, P. (2018, 11-14 July 2018). A Method for Ecological Process Optimization Based on Compliance Checking. Proceedings of the 2018 IEEE 20th Conference on Business Informatics (CBI) (Vol. 1, pp. 119-128). IEEE.

Maciel, J. C. (2017). The Core Capabilities of Green Business Process Management-A Literature Review. Proceedings of the 13th Internationalen Tagung Wirtschaftsinformatik (WI 2017), St. Gallen, S. 1526-1537.

Melnyk, S. A., Sroufe, R. P., \& Calantone, R. (2003). Assessing the impact of environmental management systems on corporate and environmental performance. Journal of Operations Management, 21(3), 329-351. 
Morgan, J., Dagnet, Y., \& Tirpak, D. (2014). Elements and ideas for the 2015 Paris agreement. Washington, DC: Agreement for Climate Transformation.

National Sustainability Council. (2013). Sustainable Australia Report. Retrieved from http://base.socioeco.org/docs/sustainable-report-full.pdf

Nerlich, B., Koteyko, N., \& Brown, B. (2010). Theory and language of climate change communication. Wiley Interdisciplinary Reviews: Climate Change, 1(1), 97-110.

Nowak, A., Binz, T., Fehling, C., Kopp, O., Leymann, F., \& Wagner, S. (2012). Pattern-driven green adaptation of process-based applications and their runtime infrastructure. Computing, 94(6), 463-487.

Nowak, A., \& Leymann, F. (2013). Green Business Process Patterns--Part II. Proceedings of the 2013 IEEE 6th International Conference on Service-Oriented Computing and Applications (pp. 168-173).

Nowak, A., Leymann, F., \& Mietzner, R. (2011a). Towards green business process reengineering. In Service-Oriented Computing (pp. 187-192): Springer.

Nowak, A., Leymann, F., Schleicher, D., Schumm, D., \& Wagner, S. (2011b). Green business process patterns. Proceedings of the 18th conference on pattern languages of programs (pp. 1-10).

Nowak, A., Leymann, F., \& Schumm, D. (2011c). The differences and commonalities between green and conventional business process management. Proceedings of the 2011 IEEE $9^{\text {th }}$ International Conference on Dependable, Autonomic and Secure Computing (pp. 569576). IEEE.

Nowak, A., Leymann, F., Schumm, D., \& Wetzstein, B. (2011). An architecture and methodology for a four-phased approach to green business process reengineering. In Information and Communication on Technology for the Fight against Global Warming (pp. 150164): Springer.

Opitz, N., Krüp, H., \& Kolbe, L. M. (2014a). Environmentally Sustainable Business Process Management-Developing a Green BPM readiness model. Proceedings of the Pacific Asia Conference on Information Systems (PACIS), Chengdu, China pp. 12.

Opitz, N., Krüp, H., \& Kolbe, L. M. (2014b). Green Business Process Management--A Definition and Research Framework. Proceedings of the 2014 47th Hawaii International Conference on System Sciences (pp. 3808-3817).

Parmenter, D. (2010). Key performance indicators (KPI): developing, implementing, and using winning KPIs: John Wiley \& Sons.

Pernici, B., Ardagna, D., \& Cappiello, C. (2008). Business process design: Towards servicebased green information systems. In E-Government Ict Professionalism and Competences Service Science (pp. 195-203): Springer.

Phan, T. N., \& Baird, K. (2015). The comprehensiveness of environmental management systems: The influence of institutional pressures and the impact on environmental performance. Journal of Environmental Management, 160(Supplement C), 45-56. doi:https://doi.org/10.1016/j.jenvman.2015.06.006. 
Porter, M. E. (2008). Competitive advantage: Creating and sustaining superior performance: Simon and Schuster.

Porter, M. E., \& Van der Linde, C. (1995). Toward a new conception of the environmentcompetitiveness relationship. The Journal of Economic Perspectives, 9(4), 97-118.

Pritchard, J.-P., \& Armistead, C. (1999). Business process management-lessons from European business. Business Process Management Journal, 5(1), 10-35.

Qin, W., \& Wang, Q. (2007). Modeling and control design for performance management of web servers via an LPV approach. IEEE Transactions on Control Systems Technology, 15(2), 259-275.

Rajeev, A., Pati, R. K., Padhi, S. S., \& Govindan, K. (2017). Evolution of sustainability in supply chain management: A literature review. Journal of Cleaner Production, 162(Supplement C), 299-314. doi:https://doi.org/10.1016/j.jclepro.2017.05.026

Recker, J., Rosemann, M., \& Gohar, E. R. (2011). Measuring the carbon footprint of business processes. In Business Process Management Workshops, Springer Berlin Heidelberg (2011), pp. 511-520

Recker, J., Rosemann, M., Hjalmarsson, A., \& Lind, M. (2012). Modeling and Analyzing the Carbon Footprint of Business Processes. In J. vom Brocke, S. Seidel, \& J. Recker (Eds.), Green Business Process Management (pp. 93-109): Springer.

Rehan, S., Bandara, W., Erica, F., \& Glenn, S. (2018). Getting it right! Critical Success Factors of BPM in the Public Sector: A Systematic Literature Review. Australasian Journal of Information Systems, 22(0). doi:10.3127/ajis.v22i0.1265

Reiter, M., Fettke, P., \& Loos, P. (2014). Towards Green Business Process Management: Concept and Implementation of an Artifact to Reduce the Energy Consumption of Business Processes. Paper presented at Hawaii International Conference on System Sciences (HICSS), 2014

Rogelj, J., den Elzen, M., Höhne, N., Fransen, T., Fekete, H., Winkler, H., . . Meinshausen, M. (2016). Paris Agreement climate proposals need a boost to keep warming well below $2{ }^{\circ} \mathrm{C}$. Nature, 534(7609), 631-639. doi:10.1038/nature18307

Roohy Gohar, S., \& Indulska, M. (2015). Business process management: saving the planet? Proceedings of the Australasian Conference on Information Systems (ACIS). Adelaide, Australia, 30 November-4 December 2015; pp. 1-14.

Rosemann, M., \& Vessey, I. (2008). Toward improving the relevance of information systems research to practice: the role of applicability checks. MIS Quarterly, 1-22.

Rosemann, M., \& vom Brocke, J. (2010). The six core elements of business process management. In Handbook on Business Process Management 1 (pp. 107-122): Springer.

Rosemann, M., \& vom Brocke, J. (2015). The Six Core Elements of Business Process Management. In J. vom Brocke \& M. Rosemann (Eds.), Handbook on Business Process Management 1 (pp. 105-122): Springer.

Sanders Jones, J. L., \& Linderman, K. (2014). Process management, innovation and efficiency performance: The moderating effect of competitive intensity. Business Process Management Journal, 20(2), 335-358. 
Savitz, A. (2012). The triple bottom line: How today's best-run companies are achieving economic, social and environmental success--and how you can too: John Wiley \& Sons.

Schlagenhaufer, C., \& Amberg, M. (2015). A Descriptive Literature Review and Classification Framework for Gamification in Information Systems. Paper presented at the European Conference on Information Systems (ECIS), Münster, Germany.

Schmidheiny, S. (1992). Changing course: A global business perspective on development and the environment (Vol. 1): MIT press.

Schoormann, T., Behrens, D., \& Knackstedt, R. (2017). Sustainability in Business Process Models: A Taxonomy-Driven Approach to Synthesize Knowledge and Structure the Field.

Seidel, S., \& Recker, J. (2012). Implementing green business processes: the importance of functional affordances of information systems. Paper presented at the ACIS 2012: Location, location, location: Proceedings of the 23rd Australasian Conference on Information Systems 2012.

Seidel, S., Recker, J., \& Brocke, J. (2012). Green Business Process Management. In J. vom Brocke, S. Seidel, \& J. Recker (Eds.), Green Business Process Management (pp. 3-13): Springer Berlin Heidelberg.

Seidel, S., Recker, J. C., Pimmer, C., \& vom Brocke, J. (2010). Enablers and barriers to the organizational adoption of sustainable business practices. Paper presented at the Proceeding of the 16th Americas conference on information systems: sustainable IT collaboration around the globe.

Seidel, S., vom Brocke, J., \& Recker, J. C. (2011). Call for action: investigating the role of business process management in green IS. Sprouts: Working Papers on Information Systems, 11(4).

Sharma, S. (2000). Managerial interpretations and organizational context as predictors of corporate choice of environmental strategy. Academy of Management journal, 43(4), 681697.

Stern, P. C., Dietz, T., Abel, T., Guagnano, G. A., \& Kalof, L. (1999). A value-belief-norm theory of support for social movements: The case of environmentalism. Human ecology review, 81-97.

Stolze, C., Semmler, G., \& Thomas, O. (2012). Sustainability in Business Process Management Research-a Literature Review. Paper presented at the AMCIS 2012, Seattle.

Sullivan, R., \& Wyndham, H. (2001). Effective environmental management. Principles and Case Studies Allen and Unwin Sydney, Australia.

Thies, H., Dada, A., \& Stanoevska-Slabeva, K. (2012). The Potential of a Network-Centric Solution for Sustainability in Business Processes. In Green Business Process Management (pp. 181-201): Springer.

Tinsley, S., \& Pillai, I. (2006). Environmental systems management: Understanding organisational drivers and barriers. In: Earthscan: London.

Triantaphyllou, E. (2000). Multi-criteria decision making methods. In Multi-criteria decision making methods: A comparative study (pp. 5-21): Springer. 
United Nations. (2016). The Sustainable Development Agenda. Retrieved from https://www.un.org/sustainabledevelopment/development-agenda.

United Nations Environment Programme. (2014). UNEP 2014 Annual Report ( DCP/1884/NA). Retrieved from http://apps.unep.org/publications/pmtdocuments/UNEP_2014_Annual_Report-2015UNEP_Annual_Report_2014_Production_LQ.pdf.pdf

Van Der Aalst, W. M. (2004). Business process management demystified: A tutorial on models, systems and standards for workflow management. In Lectures on concurrency and Petri nets (pp. 1-65): Springer.

vom Brocke, J., \& Sinnl, T. (2011). Culture in business process management: a literature review. Business Process Management Journal, 17(2), 357-378.

Wabwoba, M. F., Wanyembi, G. W., Omuterema, S., \& Omieno, M. K. K. (2013). Green ICT Readiness Model for Developing Economies: Case of Kenya. International Journal.

Wathern, P. (2013). Environmental impact assessment: theory and practice: Routledge.

World Commission on Environment and Development. (1987). Our Common Future: Report of the World Commission on the Environment and Development(WCED) [Bruntlandt Report]. General Assembly, United Nations, Forty-second Session, Supplement No. 25, A/42/25. Also published as Our Common Future. 1987. Oxford and New York: Oxford University Press.

Webster, J., \& Watson, R. T. (2002). Analyzing the past to prepare for the future: Writing a literature review. Management Information Systems Quarterly, 26(2), 3.

Weske, M. (2012). Business process management: concepts, languages, architectures: Springer Science \& Business Media.

Weske, M., van der Aalst, W. M., \& Verbeek, H. (2004). Advances in business process management. Data \& Knowledge Engineering, 50(1), 1-8.

Wesumperuma, A., Ginige, A., Ginige, J., \& Hol, A. (2013). Green activity based management $(A B M)$ for organisations. Proceedings of the 24 th Australasian Conference on Information Systems (ACIS). RMIT University; 2013; pp. 1- 11.

Wesumperuma, A., Ginige, J. A., Ginige, A., \& Hol, A. (2011). A Framework for Multi-dimensional Business Process Optimization for GHG Emission Mitigation. Proceedings of the 22nd Australasian Conference on Information Systems (ACIS), Sydney, Australia; December 2011

Wesumperuma, A. E. (2015). Multi-dimensional business process optimisation for greenhouse gas (GHG) emission management. University of Western Sydney, Australia.

Wetzstein, B., Ma, Z., \& Leymann, F. (2008). Towards measuring key performance indicators of semantic business processes. Proceedings of the International Conference on Business Information Systems (pp. 227-238). Springer, Berlin, Heidelberg.

Whitelaw, K. (2004). ISO 14001 environmental systems handbook: Routledge.

Young, C. W., \& Rikhardsson, P. M. (1996). Environmental performance indicators for business. Eco-Management and Auditing, 3(3), 113-125. 


\section{Appendix}

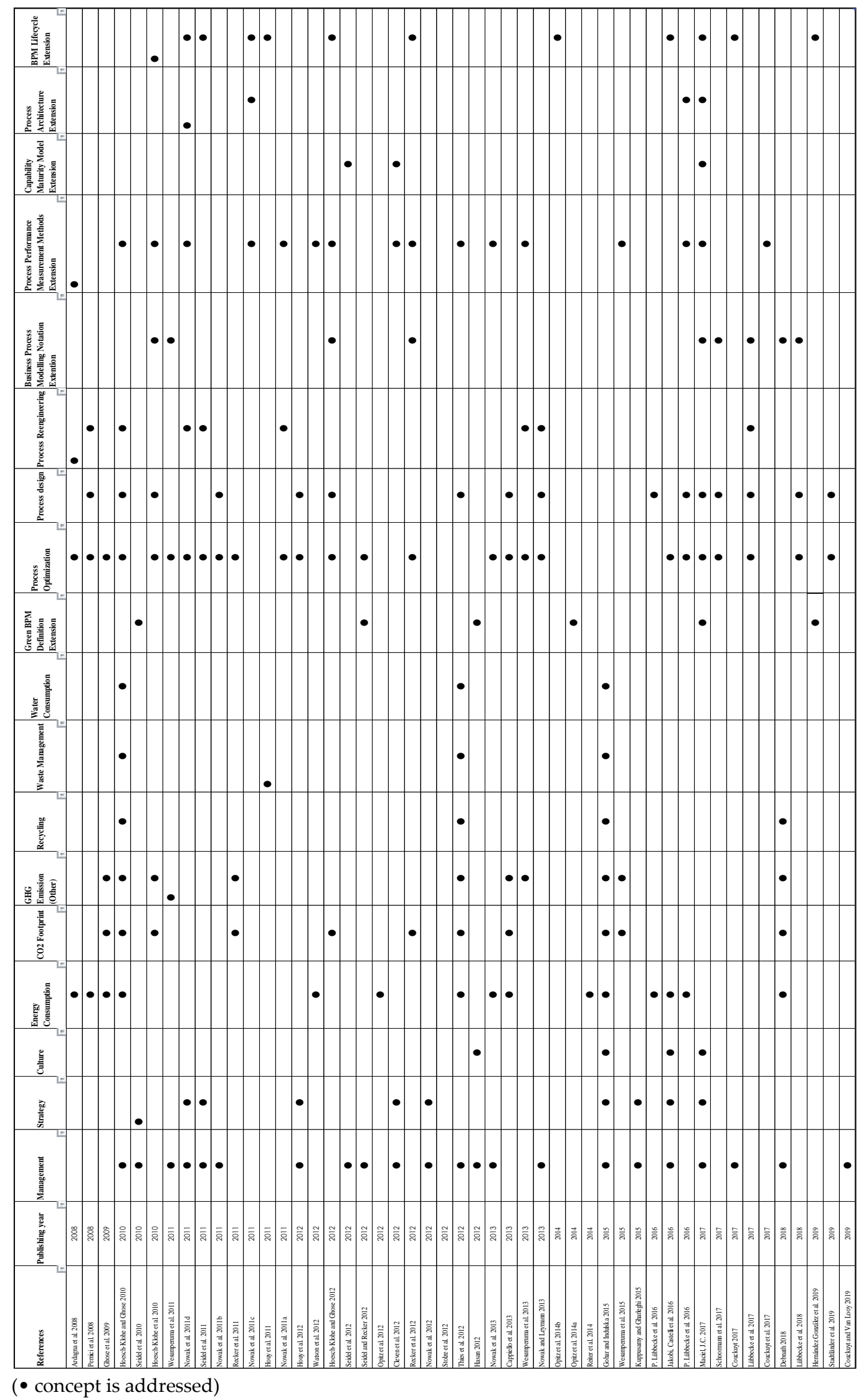

Table 5 Distribution of research contributions to ES and BPM concepts in 49 analysed papers 
Copyright: ( 2020 Roohy Gohar \& Indulska. This is an open-access article distributed under the terms of the Creative Commons Attribution-NonCommercial 3.0 Australia License, which permits non-commercial use, distribution, and reproduction in any medium, provided the original author and AJIS are credited.

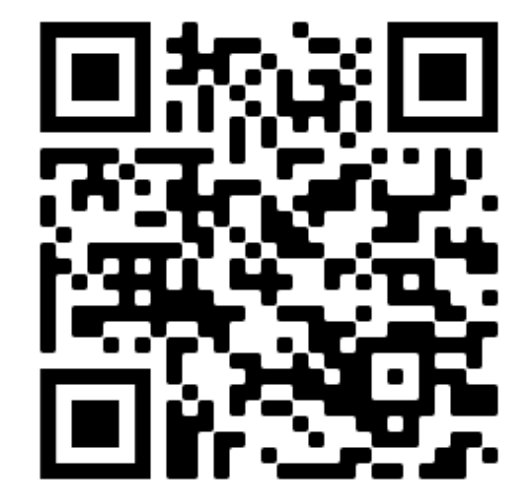

